\title{
Vertical stratification of adult mosquitoes (Diptera: Culicidae) within a tropical rainforest in Sabah, Malaysia
}

\author{
Hayley L. Brant ${ }^{*}$, Robert M. Ewers ${ }^{2}$, Indra Vythilingam ${ }^{3}$, Chris Drakeley ${ }^{4}$, Suzan Benedick \\ and John D. Mumford ${ }^{1}$
}

\begin{abstract}
Background: Malaria cases caused by Plasmodium knowlesi, a simian parasite naturally found in long-tailed and pig-tailed macaques, are increasing rapidly in Sabah, Malaysia. One hypothesis is that this increase is associated with changes in land use. A study was carried out to identify the anopheline vectors present in different forest types and to observe the human landing behaviour of mosquitoes.

Methods: Mosquito collections were carried out using human landing catches at ground and canopy levels in the Tawau Division of Sabah. Collections were conducted along an anthropogenic disturbance gradient (primary forest, lightly logged virgin jungle reserve and salvage logged forest) between 18:00 and 22:00 h.

Results: Anopheles balabacensis, a vector of $P$. knowlesi, was the predominant species in all collection areas, accounting for $70 \%$ of the total catch, with a peak landing time of 18:30-20:00 h. Anopheles balabacensis had a preference for landing on humans at ground level compared to the canopy $(p<0.0001)$. A greater abundance of mosquitoes were landing in the logged forest compared to the primary forest $(p<0.0001)$. There was no difference between mosquito abundance in the logged forest and lightly logged forest $(p=0.554)$. A higher evening temperature $(p<0.0001)$ and rainfall ( $p<0.0001$ ) significantly decreased mosquito abundance during collection nights.

Conclusions: This study demonstrates the potential ability of An. balabacensis to transmit $P$. knowlesi between canopy-dwelling simian hosts and ground-dwelling humans, and that forest disturbance increases the abundance of this disease vector. These results, in combination with regional patterns of land use change, may partly explain the rapid rise in $P$. knowlesi cases in Sabah. This study provides essential data on anthropophily for the principal vector of P. knowlesi which is important for the planning of vector control strategies.
\end{abstract}

Keywords: Anopheles balabacensis, Vector, Plasmodium knowlesi, Deforestation, Malaysia

\section{Background}

Malaria still remains a public health problem throughout tropical and sub-tropical regions of the world, with an estimated 214 million new cases and 438,000 deaths in 2015 [1]. Four Plasmodium species are recognised as causing human malaria; Plasmodium falciparum, Plasmodium malariae, Plasmodium ovale and Plasmodium

\footnotetext{
*Correspondence: hayleylbrant@gmail.com

${ }^{1}$ Faculty of Natural Sciences, Centre for Environmental Policy, Imperial College London, Silwood Park Campus, Buckhurst Road, Ascot SL5 7PY, UK

Full list of author information is available at the end of the article
}

vivax, but recently a fifth species, Plasmodium knowlesi, has been recognized as causing symptomatic malaria in humans [2-4]. Plasmodium knowlesi, transmitted by the forest-dwelling Anopheles from the Leucosphyrus group, is an emerging cause for zoonotic human malaria in Southeast Asia [3, 5-7]. Malaysia has had a successful malaria control programme, aimed to eliminate malaria by 2020 , with marked reductions in reported cases of $P$. falciparum and $P$. vivax, but there has been a recent increase in P. knowlesi cases [8-11]. Plasmodium knowlesi is now the most common cause of malaria in the Malaysian state of Sabah, accounting for $62 \%$ of all 
malaria incidences in 2013 and presenting a threat to malaria elimination [8].

It has been proposed that land use change, including deforestation, forest fragmentation and agricultural practices, has increased the incidence of $P$. knowlesi by increasing the encroachment of humans into previously forested areas, allowing a higher interaction between vectors and human and macaque hosts $[9,12]$. The increase in P. knowlesi cases may also be underestimated due to misdiagnosis during microscopic examination [13, 14]. Microscopy of stained blood smears allows differentiation between species, but frequent misdiagnosis occurs in areas containing $P$. falciparum, $P$. vivax and $P$. knowlesi [14].

Monkeys, particularly the long-tailed macaque (Macaca fascicularis) and the pig-tailed macaque (Macaca nemestrina) found in Southeast Asia, are the two main natural hosts of $P$. knowlesi [15]. A study in Sabah showed nearly all patients with $P$. knowlesi malaria had a recent history of forest or forest-edge exposure, and had seen a monkey in the preceding month [16]. Most members of the Leucosphyrus group, from the genus Anopheles, feed primarily on monkeys in the canopy and are capable of transmitting various Plasmodium species [17]. Anopheles balabacensis is the predominant vector of human malaria in Sabah [18, 19], and has also been incriminated as a $P$. knowlesi vector [20,21].

Most primates are arboreal. Although some species of chimpanzees, baboons and macaques rest and feed at ground level during the day, primates almost always sleep in the canopy during the night [22]. As Anopheles species generally bite between 6 p.m. and 6 a.m., primate roosting sites are potentially a key location for disease transmission between primate hosts. It is hypothesized that vectors are biting humans at ground level, but if given the opportunity, will bite at canopy level. This study expects that key vector species should be present in the disturbed forest habitats where people come into contact with monkeys, but it is unknown which species should expect to be present in primary forest.

Since transmission is increasing in Sabah, it is important to identify the $P$. knowlesi vectors present and understand their biting behaviour within forest habitats. While other vector assessments are ongoing in the Interior, West Coast, Kudat and Sandakan Divisions in Sabah, the Tawau Division has not been studied. This study was conducted to determine the vertical distribution of mosquitoes and their biting preference in Sabah, Malaysia.

\section{Methods}

\section{Study site}

The study was conducted in the Tawau Division of Sabah, Malaysia. Three areas were selected along a forest disturbance gradient; primary lowland dipterocarp rainforest $(\mathrm{PF})$, virgin jungle reserve $(\mathrm{VJR})$ and twice-logged disturbed dipterocarp rainforest (LF) with forest disturbance quantified using on-the-ground forest plots [23]. Primary forest survey points were selected in the vicinity of Danum Valley Field Centre $\left(4^{\circ} 58^{\prime} \mathrm{N}, 117^{\circ} 42^{\prime} \mathrm{E}\right)$, located within the Danum Valley Conservation Area. This area consists of 43,800 ha of protected dipterocarp rainforest [24]. Virgin jungle reserve $\left(4^{\circ} 40^{\prime} \mathrm{N}, 117^{\circ} 32^{\prime} \mathrm{E}\right)$ and logged forest survey points $\left(4^{\circ} 41^{\prime} \mathrm{N}, 117^{\circ} 34^{\prime} \mathrm{E}\right)$ were selected within the Benta Wawasan oil palm plantation. The 45,601 ha area is a mixture of twice-logged rainforest, virgin jungle reserve, acacia and oil palm. The VJR, of 2200 ha, has been logged around the edge, but never logged in the steep interior [25]. Survey points were selected 500$1000 \mathrm{~m}$ from the VJR edge in locations that had undergone light logging. Logged forest survey points were in selectively twice-logged forest, logged during 1970s, 1990s-2000s resulting in the cumulative removal of $\sim 180 \mathrm{~m}^{3} \mathrm{ha}^{-1}$ of timber [26], and currently being further disturbed by additional salvage logging activity in surrounding areas. Further details of the project area are given by Ewers et al. [25].

Three survey points, with a minimum separation distance of $500 \mathrm{~m}$, were selected in each area. One tree was selected at each point based on its accessibility into the canopy, low density of epiphytes and height. Visual tree assessments were carried out to make sure every tree was safe to climb. The trees selected ranged from a height of $15 \mathrm{~m}$ in the logged forest to $30 \mathrm{~m}$ in the virgin jungle reserve and primary forest. Survey points were a subset of those designated as part of the central sampling design of the 'Stability of Altered Forest Ecosystems (SAFE) Project', a large-scale fragmentation experiment, which is investigating the long-term effects of forest fragmentation [25].

\section{Data collection}

All data collection was carried out from April to July 2014, and mosquitoes were collected using human landing catches at ground and canopy height between 18:00 and 22:00 h. Four consecutive nights of collections were carried out in PF and VJR, and five nights in LF, using a rotation of collectors. Access was gained into the canopy using line insertion to high branches [27], followed by the double rope climbing technique taught by Canopy Access Limited [28]. Canopy samples were collected at a height of two-thirds the average canopy height at that location $(10-20 \mathrm{~m})$. Ground and canopy collections were conducted simultaneously. The average canopy height surrounding each selected tree was calculated using a laser rangefinder. 
The collectors, with the aid of a red torch-light, aspirated mosquitoes off their own legs. Collected mosquitoes were placed into cups covered with a net cloth, and a new cup was used during every half an hour of collection. Mosquitoes were taken back to the field laboratory to be killed and sorted into individual tubes with silica gel. All mosquitoes were identified morphologically using keys [29-35].

\section{Meteorological data}

Air temperature $\left({ }^{\circ} \mathrm{C}\right)$ and relative humidity (\%) were measured at each site using microclimate dataloggers at the base and in the canopy of each tree during sampling. Nightly rainfall $(\mathrm{mm})$ data were obtained from the nearest rain gauges located at SAFE Project and Danum Valley Field Centre for the duration of the field survey (March to July 2014; range 1.0-3.5 km from sample sites). In addition, lunar illumination (\%), cloud cover and unusual climatic events (e.g. strong winds) were recorded every half an hour by the collectors.

\section{Data analysis}

Analyses were performed using $\mathrm{R}$ version 3.1.1 [36]. Simpson and Shannon diversity indices were calculated in each area using the vegan function 'diversity' ( $R$ package vegan, 'diversity') [37]. Species accumulation curves were calculated in each area using the vegan function 'specaccum' (R package vegan, 'specaccum') [37]. To estimate the number of undetected species and add them to the observed richness, true richness estimators were used. These estimators included the Chao species estimator (Chao 1) and Abundance Coverage Estimator (ACE). Chao 1 and ACE were used to estimate the extrapolated species richness in each area using 'chao1' and 'ACE' functions in the $\mathrm{R}$ package 'fossil' ( $\mathrm{R}$ package fossil, 'chao1', 'ACE') [38].

The effect of canopy height (a dichotomous variable representing ground or canopy level) and forest disturbance (PF, VJR and LF) on mosquito abundance was analysed using a generalized linear mixed-effect model (R package lme4) [39], using day and site as random factors, with Poisson error distribution. Chi squared tests were used to compare the relative abundance of vector and non-vector species in each area, and between ground and canopy level. Differences in community composition at ground and canopy height were explored using Detrended Correspondence Analysis (DCA, vegan function 'decorana') [37]. The number of mosquitoes landing per night was used as a measure of relative abundance. Significant differences were tested for in community composition using a linear model with the first DCA axis as the response variable against canopy height and forest disturbance.

\section{Results}

\section{Mosquito abundance}

A total of 807 mosquitoes were collected from 39 human landing catch nights, consisting of 743 (92.1\%) anophelines, and $64(7.9 \%)$ culicines. A total of $555(68.8 \%)$ mosquitoes from 21 species were found at ground level in comparison to 252 (31.2\%) mosquitoes from 10 species at canopy level. Anopheles balabacensis was the predominant species at ground (62.4-87.5\% of all individuals) and canopy level (43.4-73.5 \%) at each collection site. A full list of species is given in Table 1 .

The number of species collected, Shannon index, Simpson index, Chao1 and ACE varied across forest disturbance and between ground and canopy level (Tables 2,3). The Chao 1 and ACE predicted a higher number of species in the logged forest than the primary forest, and a higher number of species at ground level (Tables 2,3). These patterns were also seen with the number of species collected, Shannon index and Simpson index. The species accumulation curves did not reach an asymptote at ground and canopy level, indicating not all species of mosquitoes had been collected (see Additional file 1).

\section{Effect of height and forest disturbance on mosquito abundance}

Mosquito abundance in the canopy was significantly lower than at ground level $\left(\mathrm{x}^{2}=81.89, \mathrm{df}=1, \mathrm{p}<0.0001\right)$ (Table 4; Fig. 1a). Logged forest had a higher abundance than virgin jungle reserve or primary forest $\left(X^{2}=10.94\right.$, $\mathrm{df}=2, \mathrm{p}<0.05$ ) (Fig. 1a). Similar patterns were seen with abundance of An. balabacensis (Table 4; Fig. 1b). Rainfall and a higher evening temperature decreased mosquito abundance $\left(\mathrm{X}^{2}=14.55, \mathrm{df}=1, \mathrm{p}<0.0001\right)$, whereas moonlight increased the abundance $\left(x^{2}=4.49, \mathrm{df}=1\right.$, $\mathrm{p}<0.05$ ) (Table 4). Collector identity had no effect on mosquito abundance $\left(x^{2}=3.871, \mathrm{df}=2, \mathrm{p}=0.144\right)$. Peak biting of An. balabacensis during the collection period was observed between 19:00 and 20:00 h in logged forest and virgin jungle reserve (Fig. 2).

\section{Community composition}

The DCA plot indicated that the community composition of the canopy was significantly different to ground level collection and across forest disturbance, with the community from the two height strata being strongly separated on the first axis $\left(\mathrm{F}_{1,60}=24.72, \mathrm{p}<0.0001\right.$, Fig. 3$)$. The communities in the three categories of forest disturbance were not separated along the first axis $\left(\mathrm{F}_{2,60}=0.92\right.$, $\mathrm{p}=0.4$ ), but the interaction between height and forest disturbance was significant $\left(\mathrm{F}_{2,60}=8.37, \mathrm{p}<0.001\right)$. The first two axes accounted for $66.9 \%$ of the total variance. Anopheles balabacensis was prevalent at both ground 
Table 1 Mosquitoes collected from different collection sites in the district of Tawau, Sabah, Malaysia

\begin{tabular}{|c|c|c|c|c|c|c|}
\hline \multirow[t]{3}{*}{ Mosquito genera and species } & \multicolumn{6}{|c|}{ Number collected at: } \\
\hline & \multicolumn{2}{|c|}{ Primary forest } & \multicolumn{2}{|c|}{ Virgin jungle reserve } & \multicolumn{2}{|c|}{ Logged forest } \\
\hline & Ground & Canopy & Ground & Canopy & Ground & Canopy \\
\hline Am. orbitae & 0 & 0 & 0 & 0 & 1 & 0 \\
\hline An. Aitkenii group & 0 & 0 & 21 & 0 & 18 & 0 \\
\hline An. barbirostris & 0 & 0 & 1 & 0 & 3 & 0 \\
\hline An. sp. ${ }^{a}$ & 0 & 0 & 1 & 0 & 10 & 3 \\
\hline An. balabacensis & 21 & 12 & 83 & 23 & 296 & 130 \\
\hline An. latens & 0 & 1 & 1 & 5 & 1 & 1 \\
\hline An. macarthuri & 0 & 1 & 10 & 4 & 16 & 5 \\
\hline An. maculatus & 1 & 0 & 7 & 2 & 12 & 4 \\
\hline An. watsonii & 1 & 6 & 3 & 15 & 14 & 11 \\
\hline Arm. confusus & 0 & 0 & 1 & 0 & 0 & 0 \\
\hline Arm. jugraensis & 0 & 0 & 0 & 0 & 5 & 0 \\
\hline Arm. sp. ${ }^{a}$ & 0 & 0 & 1 & 0 & 0 & 0 \\
\hline Col.pseudotaeniatus & 0 & 0 & 1 & 0 & 0 & 0 \\
\hline Coq. crassipes & 0 & 0 & 0 & 1 & 0 & 1 \\
\hline Cx. sitiens & 0 & 0 & 0 & 0 & 5 & 1 \\
\hline Cx.vishnui & 0 & 0 & 0 & 0 & 2 & 0 \\
\hline Cx. (Lophoceraomyia) & 0 & 0 & 0 & 0 & 1 & 0 \\
\hline Do.ganapathi & 1 & 2 & 0 & 3 & 4 & 16 \\
\hline Pr. ostentatio & 0 & 0 & 1 & 0 & 0 & 0 \\
\hline Ph. prominens & 0 & 0 & 0 & 0 & 1 & 0 \\
\hline Stg. albopicta & 0 & 0 & 0 & 0 & 4 & 0 \\
\hline Stg. sp..$^{a}$ & 0 & 0 & 1 & 0 & 4 & 2 \\
\hline Ve. sp. ${ }^{a}$ & 0 & 0 & 1 & 0 & 1 & 3 \\
\hline Total mosquitoes & 24 & 22 & 133 & 53 & 398 & 177 \\
\hline No. of collection nights & 12 & 12 & 12 & 12 & 15 & 15 \\
\hline Mosquitoes/nights & 2 & 1.8 & 11.1 & 4.42 & 26.5 & 11.8 \\
\hline
\end{tabular}

a Couldn't be identified to species level

Table 2 Mean species richness and diversity indices $( \pm \mathrm{SE})$ of mosquito communities, collected at ground level

\begin{tabular}{|c|c|c|c|c|c|c|}
\hline \multirow[t]{2}{*}{ Forest disturbance } & \multicolumn{6}{|c|}{ Human landing catches } \\
\hline & $\mathbf{N}$ & Species no. & Shannon index & Simpson index & Chao1 & $\mathrm{ACE}$ \\
\hline PF & 12 & 4 & $0.06(0.04)$ & $0.45(0.14)$ & 7 & 7 \\
\hline VJR & 12 & 14 & $0.70(0.10)$ & $0.40(0.05)$ & 50 & 19.4 \\
\hline LF & 15 & 18 & $0.88(0.12)$ & $0.43(0.06)$ & 30.5 & 19.8 \\
\hline
\end{tabular}

Mean species richness and diversity indices ( \pm SE) of mosquito communities, collected at ground level using human landing catches, in primary forest $P F$, virgin jungle reserve $V J R$ and logged forest $L F$

and canopy level, but the ground level community also included species such as Anopheles barbirostris, Armigeres jugraensis, Culex vishnui and the Anopheles Aitkenii group, which were not present in the canopy. The species turnover that causes the difference in community composition between ground and canopy was driven by species that have not been reported to cause disease transmission.

\section{Discussion}

Studying the anthropophily of simian malaria vectors in the canopy of tropical forests is essential because the hosts are primarily arboreal. In order to develop, sustain or adapt a good control programme, it is important to monitor mosquito populations as well as their hosts and host-seeking preference, distribution and behaviour. Although previous studies in 
Table 3 Mean species richness and diversity indices $( \pm \mathrm{SE})$ of mosquito communities, collected at canopy level

\begin{tabular}{|c|c|c|c|c|c|c|}
\hline \multirow{2}{*}{$\begin{array}{l}\text { Forest } \\
\text { disturbance }\end{array}$} & \multicolumn{6}{|c|}{ Human landing catches } \\
\hline & $\mathbf{N}$ & Species no. & Shannon index & Simpson index & Chao1 & ACE \\
\hline $\mathrm{PF}$ & 12 & 5 & $0.24(0.13)$ & $0.65(0.12)$ & 7 & 6 \\
\hline VJR & 12 & 7 & $0.71(0.15)$ & $0.50(0.09)$ & 7.5 & 7.36 \\
\hline LF & 15 & 11 & $0.56(0.11)$ & $0.32(0.06)$ & 15.5 & 12.41 \\
\hline
\end{tabular}

Mean species richness and diversity indices ( \pm SE) of mosquito communities, collected at canopy level using human landing catches, in primary forest $P F$, virgin jungle reserve VJR and logged forest $L F$

Table 4 Effects of parameters on mosquito abundance

\begin{tabular}{|c|c|c|c|c|c|c|c|c|}
\hline \multirow[t]{2}{*}{ Predictor } & \multicolumn{4}{|c|}{ All species } & \multicolumn{4}{|c|}{ Anopheles balabacensis } \\
\hline & $\beta$ & SE & z & $\mathbf{p}$ & $\beta$ & SE & $z$ & $p$ \\
\hline Intercept & 10.367 & 1.241 & 8.356 & $<0.0001^{* * *}$ & 10.233 & 1.423 & 7.190 & $<0.0001^{* * *}$ \\
\hline Height & -0.050 & 0.006 & -8.804 & $<0.0001^{* * *}$ & -0.060 & 0.007 & -8.348 & $<0.0001^{* * *}$ \\
\hline Area PF & -2.268 & 0.545 & -4.165 & $<0.0001^{* * *}$ & -2.147 & 0.676 & -3.176 & $0.001^{* *}$ \\
\hline Area VJR & -0.307 & 0.518 & -0.593 & 0.554 & -0.633 & 0.657 & -0.965 & 0.335 \\
\hline Temperature & -0.295 & 0.047 & -6.330 & $<0.0001^{* * *}$ & -0.307 & 0.053 & -5.788 & $<0.0001^{* * *}$ \\
\hline Rainfall & -0.427 & 0.100 & -4.306 & $<0.0001^{* * *}$ & -0.448 & 0.115 & -3.883 & $<0.0001^{* * *}$ \\
\hline Moonlight & 0.006 & 0.003 & 2.129 & $0.033^{*}$ & 0.007 & 0.003 & 2.507 & $0.012^{*}$ \\
\hline
\end{tabular}

Effects of height, area and habitat characteristics on daily mosquito abundance of all species combined, and on Anopheles balabacensis abundance separately in primary forest $P F$, virgin jungle reserve VJR and logged forest $L F$. Coefficient estimates ( $\beta$ ), standard errors, associated Wald's z-score, and p values are given

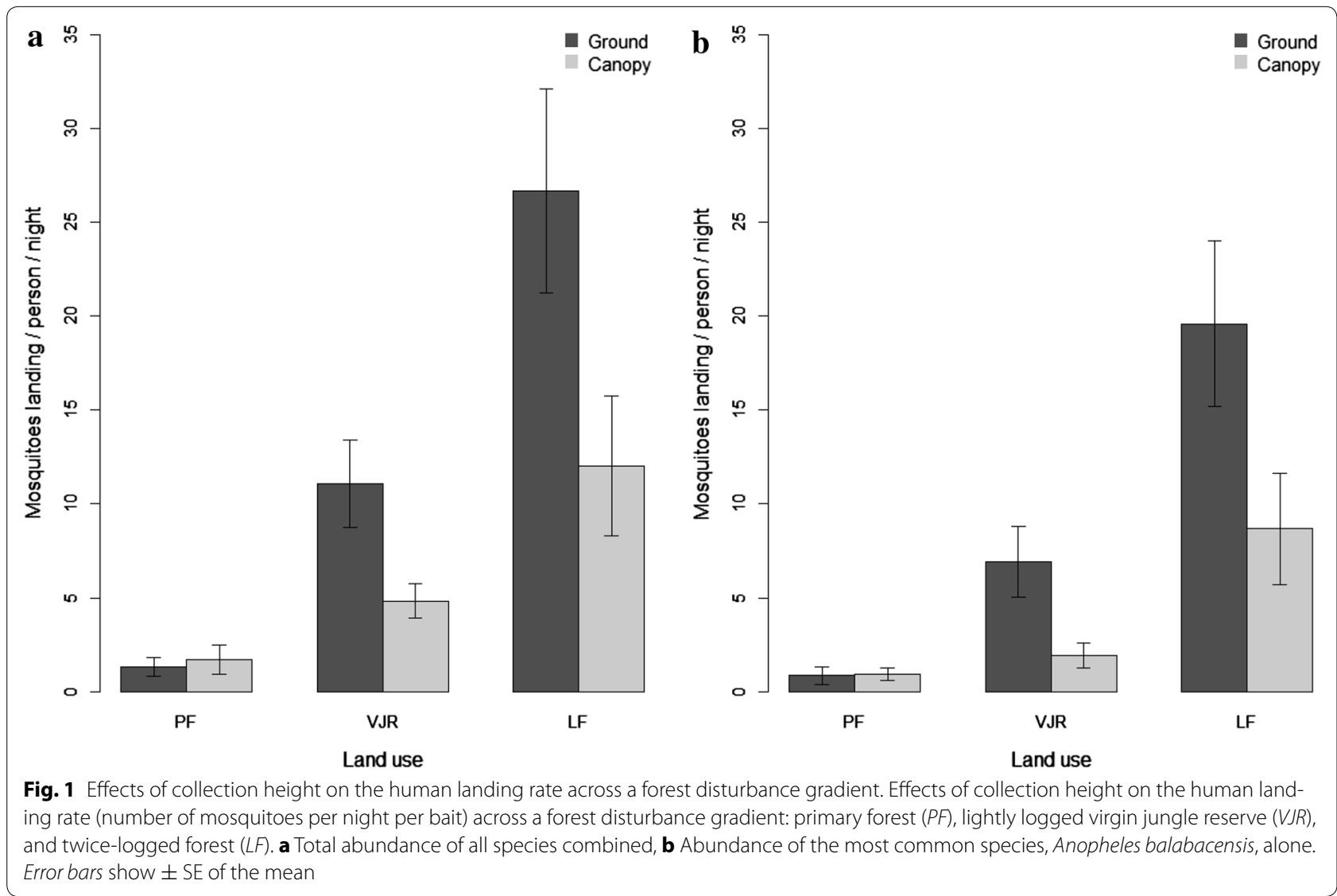



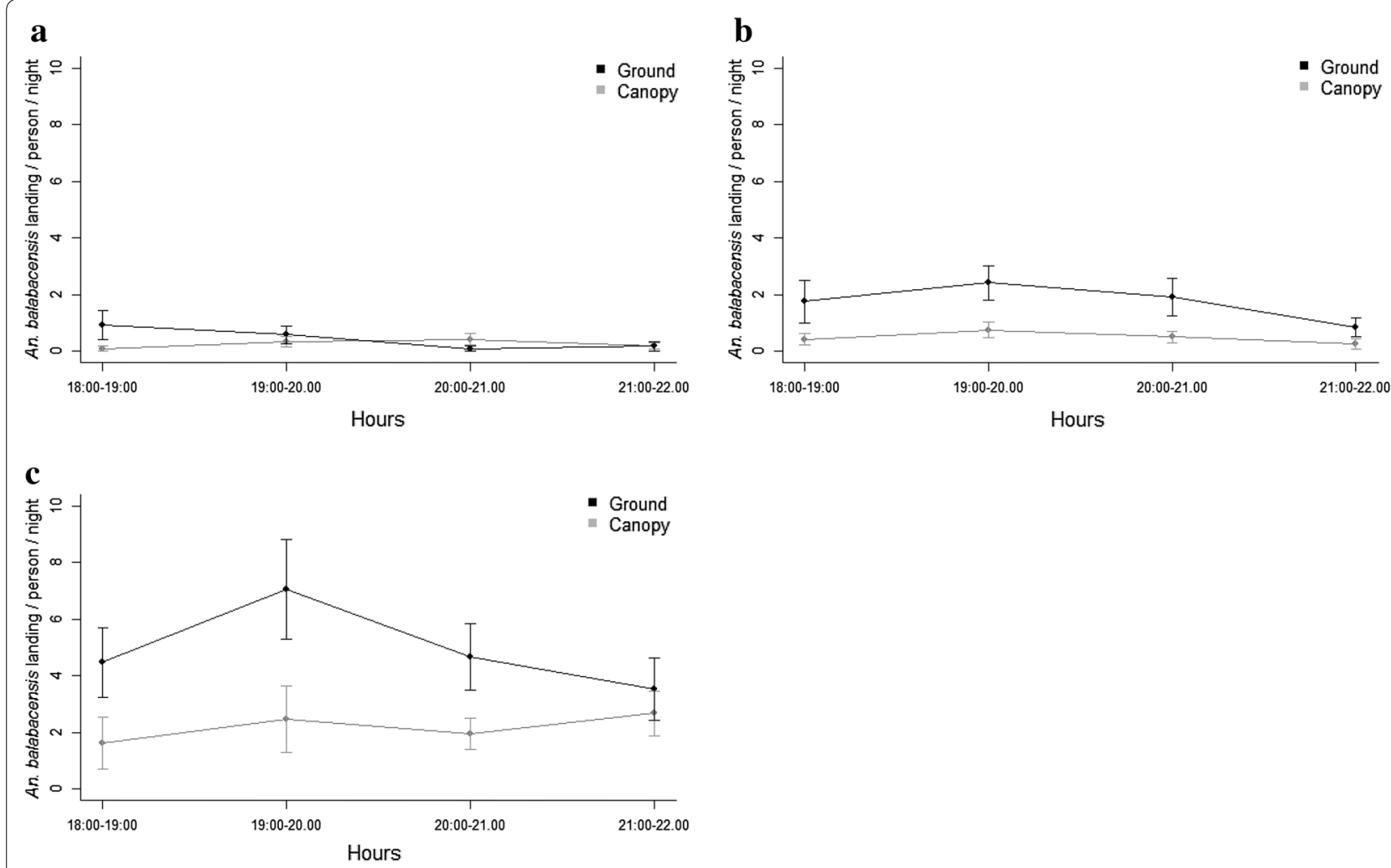

Fig. 2 Hourly number of Anopheles balabacensis landing per person per night. Hourly number of Anopheles balabacensis landing per person per night, at ground and canopy level, across an anthropogenic disturbance gradient from a Primary forest, $\mathbf{b}$ Virgin jungle reserve and $\mathbf{c}$ Logged forest. Errorbars show $\pm \mathrm{SE}$ of the mean

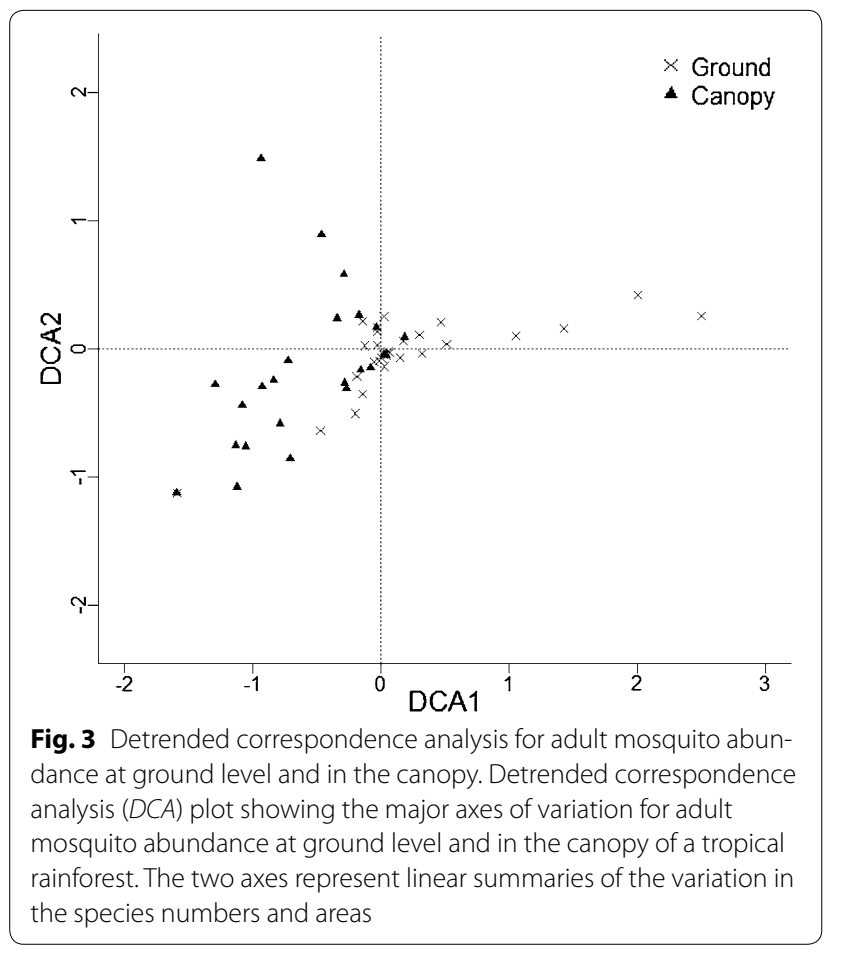

Southeast Asia have used monkey-baited traps at different canopy heights [12, 40, 41], this is the first study to attempt human landing catches, using this method, in the canopy. This study found that there was a higher abundance and human landing rate of mosquitoes at ground level, where people tend to be, than in the canopy where the simian hosts reside. This trend was driven by An. balabacensis, a key malaria vector in Sabah, and highlights the potential importance of this species in transmitting Plasmodium species from simian to human hosts.

Anopheles balabacensis was the most abundant mosquito in all sampled areas, accounting for $70 \%$ of all collected species. Anopheles balabacensis is considered the most important vector of human malaria parasites on Banggi Island and mainland Sabah, Malaysia [18, 19, 30, 42]. In Sabah, An. balabacensis was found to be mainly exophagic, but could also be endophagic and exophilic [30, 43]. These behaviours cause An. balabacensis to be an effective vector of $P$. knowlesi from human to primate hosts. There were also two distinct subpopulations, one more zoophilic and one more anthropophilic [44-46]. Anopheles balabacensis occurs in forested areas, and 
readily bites human and monkey hosts, making it an ideal vector of simian malaria $[20,47]$.

Currently insecticide-treated bed nets and indoor residual spraying are the two main control methods in Malaysia [48]. This study showed An. balabacensis bites as early as 18:00 $\mathrm{h}$ in the Tawau Division. Other studies have shown the species bites as early as 18:00 $\mathrm{h}$ in recent years in comparison to late night biters in previous decades [44, 49-51]. Given that An. balabacensis is early evening biting, highly anthropophilic, exophagic and exophilic, current control methods are not sufficient to break the transmission cycle of P. knowlesi [52]. In Vietnam and Cambodia, long-lasting insecticidal hammocks (LLIH) were shown to reduce malaria incidence and prevalence in forested areas, and may prove to be an additional effective tool in reduction of malaria in Malaysia [52-54]. The use of repellents have been used for malaria control, but need to be tested in forest and plantations areas.

This study found a different community composition of mosquitoes in the canopy to that at ground level. Different mosquito species have particular flight distributions, with certain species flying and feeding close to ground, some species showing a preference for higher canopy heights, while others show a random distribution [55, 56]. The percentage biting at different canopy heights can be affected by microclimate conditions, such as relative humidity, temperature, wind speed and rainfall $[57,58]$, but may also change according to time of day [59].

Moonlight appeared to have a significant impact on mosquito activity, with human landing rates increasing on bright nights. Although some studies have shown moonlight increases relative abundance of biting vectors [60-64], others have shown a decrease [65-68] or no effect at all [69]. Collection bias was reduced in this study by collecting in each area under different phases of the moon.

This study also showed how forest disturbance affected mosquito abundance, species richness and human landing rates. Vector abundance was greater in the lightly modified virgin jungle reserve and heavily modified logged forest than in the unmodified primary forest. These results may be explained by the availability of larval breeding sites. Wheel tracks in logged areas due to logging activities can provide breeding sites for a range of mosquito species, whereas wheel tracks are not present within primary forests or virgin jungle reserves [31]. Species richness, estimated by the Chao1 index and ACE, differed across forest disturbance and height, with logged forest and ground level having a higher species richness than primary forest and canopy.

\section{Conclusions}

This study has given an overview of mosquito species found in the Tawau Division, including the anthropophily of $P$. knowlesi vectors at canopy and ground levels. Anopheles balabacensis was the predominant species found in primary forest, virgin jungle reserve and logged forest with a preference for landing on humans at ground level. As An. balabacensis is a vector of human and simian malaria, these findings will be useful for the planning of control strategies of malaria vectors.

\section{Additional file}

Additional file 1. Species accumulation curves for human landing catch sampling in primary forest at (a) Ground and (b) Canopy level, virgin jungle reserve at (c) Ground and (d) Canopy level, and logged forest at (e) Ground and (f) Canopy level. Shaded area indicates $95 \%$ confidence intervals.

\section{Abbreviations}

ACE: abundance coverage estimator; DCA: detrended correspondence analysis; LF: logged forest; LLIH: long-lasting insecticidal hammocks; PF: primary forest; VJR: virgin jungle reserve.

\section{Authors' contributions}

HLB conducted the fieldwork, analysis and wrote the manuscript. HLB, RME, IV, CD and JDM were involved in the design of the study. RME and JDM supervised the study. All authors read and approved the final manuscript.

\section{Author details \\ ${ }^{1}$ Faculty of Natural Sciences, Centre for Environmental Policy, Imperial College London, Silwood Park Campus, Buckhurst Road, Ascot SL5 7PY, UK. ${ }^{2}$ Depart- ment of Life Sciences, Faculty of Natural Sciences, Imperial College London, Silwood Park Campus, Buckhurst Road, Ascot, Berkshire SL5 7PY, UK. ${ }^{3}$ Depart- ment of Parasitology, Faculty of Medicine, University of Malaya, 50603 Kuala Lumpur, Malaysia. ${ }^{4}$ Department of Immunology and Infection, Faculty of Infectious and Tropical Diseases, London School of Hygiene and Tropical Medicine, London WC1E 7HT, UK. ${ }^{5}$ Faculty of Sustainable Agriculture, Univer- siti Malaysia Sabah, Locked Bag No. 3, 90509 Sandakan, Sabah, Malaysia.}

\section{Acknowledgements}

For research permission, we thank the Sabah Biodiversity Council, Royal Society Southeast Asia Rainforest Research Project, Maliau Basin Management Committee, SAFE Project, Danum Valley Management Committee, Benta Wawasan, National Institute of Health, Institute for Medical Research, Medical Research and Ethics Committee and Ministry of Health. Thanks to SAFE Project coordinators (M. Khoo, R. Gray) and research assistants. We would like to thank the Natural Environmental Research Council (NE/I527902/1) and the Sime Darby Foundation for funding this work. This paper represents a contribution to Imperial College's Grand Challenges in Ecosystems and the Environment initiative.

\section{Competing interests}

The authors declare that they have no competing interests.

\section{Availability of data and material}

Data is available in the SAFE Project database (http://www.safe.earthcape. com).

\section{Ethics approval and consent to participate}

This project was approved by the Medical Research and Ethics Committee (NMRR-12-689-12521), Ministry of Health, Malaysia and Imperial College London Research Ethics Committee (ICREC-12-5-6), UK. 


\section{Funding}

This research was funded by Natural Environmental Research Council (NE/ 1527902/1).

\section{Received: 10 May 2016 Accepted: 4 July 2016}

Published online: 19 July 2016

\section{References}

1. WHO. World malaria report. Geneva: World Health Organization; 2015 (2015).

2. White NJ. Plasmodium knowlesi: The fifth human malaria parasite. Clin Infect Dis. 2008;46:172-3.

3. Cox-Singh J, Davis TME, Lee K-S, Shamsul SSG, Matusop A, Ratnam S, et al. Plasmodium knowlesi malaria in humans is widely distributed and potentially life threatening. Clin Infect Dis. 2008;46:165-71.

4. Singh B, Kim Sung L, Matusop A, Radhakrishnan A, Shamsul SSG, CoxSingh J, et al. A large focus of naturally acquired Plasmodium knowlesi infections in human beings. Lancet. 2004:363:1017-24.

5. Kantele A, Jokiranta TS. Review of cases with the emerging fifth human malaria parasite, Plasmodium knowlesi. Clin Infect Dis. 2011:52:1356-62.

6. Antinori S, Galimberti L, Milazzo L, Corbellino M. Plasmodium knowlesi: the emerging zoonotic malaria parasite. Acta Trop. 2013;125:191-201.

7. Millar SB, Cox-Singh J. Human infections with Plasmodium knowlesizoonotic malaria. Clin Microbiol Infect. 2015;21:640-8.

8. William T, Jelip J, Menon J, Anderios F, Mohammad R, Mohammad TAA, et al. Changing epidemiology of malaria in Sabah, Malaysia: increasing incidence of Plasmodium knowlesi. Malar J. 2014:13:390.

9. William T, Rahman HA, Jelip J, Ibrahim MY, Menon J, Grigg MJ, et al. Increasing incidence of Plasmodium knowlesi malaria following control of P. falciparum and P. vivax malaria in Sabah, Malaysia. PLoS Negl Trop Dis. 2013;7:e2026

10. Rajahram GS, Barber BE, William T, Menon J, Anstey NM, Yeo TW. Deaths due to Plasmodium knowlesi malaria in Sabah, Malaysia: association with reporting as Plasmodium malariae and delayed parenteral artesunate. Malar J. 2012:11:284.

11. Yusof R, Lau YL, Mahmud R, Fong MY, Jelip J, Ngian HU, et al. High proportion of knowlesi malaria in recent malaria cases in Malaysia. Malar J. 2014;13:168.

12. Vythilingam I, Noorazian YM, Huat TC, Jiram Al, Yusri YM, Azahari AH, et al. Plasmodium knowlesi in humans, macaques and mosquitoes in peninsular Malaysia. Parasit Vectors. 2008;1:26.

13. Singh B, Daneshvar C. Human infections and detection of Plasmodium knowlesi. Clin Microbiol Rev. 2013;26:165-84

14. Barber BE, William T, Grigg MJ, Yeo TW, Anstey NM. Limitations of microscopy to differentiate Plasmodium species in a region co-endemic for Plasmodium falciparum, Plasmodium vivax and Plasmodium knowlesi. Malar J. 2013;12:8

15. Garnham PCC. Malaria parasites and other haemosporidia. Oxford: Blackwell Scientific Publications Ltd: 1966

16. Barber BE, William T, Grigg MJ, Menon J, Auburn S, Marfurt J, et al. A prospective comparative study of knowlesi, falciparum, and vivax malaria in Sabah, Malaysia: high proportion with severe disease from Plasmodium knowlesi and Plasmodium vivax but no mortality with early referral and artesunate therapy. Clin Infect Dis. 2013;56:383-97.

17. Sallum MAM, Peyton EL, Wilkerson RC. Six new species of the Anopheles Leucosphyrus group, reinterpretation of An. elegans and vector implications. Med Vet Entomol. 2005;19:158-99.

18. Hii JLK, Vun YS. A study of dispersal, survival and adult population estimates of the malaria vector, Anopheles balabacensis Baisas (Diptera: Culicidae) in Sabah, Malaysia. Trop Biomed. 1985:2:121-31.

19. Khoon CC. Status of malaria vectors in Malaysia. Southeast Asian J Trop Med Publ Health. 1985:16:133-8.

20. Vythilingam I. Plasmodium knowlesi in humans: a review on the role of its vectors in Malaysia. Trop Biomed. 2010;27:1-12.

21. Collins WE, Contacos PG, Guinn EG. Studies on the transmission of simian malarias II. Transmission of the H strain of Plasmodium knowlesi by Anopheles balabacensis balabacensis. J Parasitol. 1967;53:841-4.
22. Anderson JR. Sleep-related behavioural adaptations in free-ranging anthropoid primates. Sleep Med Rev. 2000;4:355-73.

23. Pfeifer M, Lefebvre V, Turner E, Cusack J, Khoo M, Chey VK, et al. Deadwood biomass: an underestimated carbon stock in degraded tropical forests? Environ Res Lett. 2015;10:044019.

24. Marsh CW, Greer AG. Forest land-use in Sabah, Malaysia: an introduction to Danum Valley. Philos Trans R Soc Lond B Biol Sci. 1992;335:331-9.

25. Ewers RM, Didham RK, Fahrig L, Ferraz G, Hector A, Holt RD, et al. A large-scale forest fragmentation experiment: the stability of altered forest ecosystems project. Philos Trans R Soc Lond B Biol Sci. 2011;366:3292-302.

26. Struebig MJ, Turner A, Giles E, Lasmana F, Tollington S, Bernard H, et al. Quantifying the biodiversity value of repeatedly logged rainforests: gradient and comparative approaches from Borneo. Adv Ecol Res. 2013;48:183-224

27. Ellwood MDF, Foster WA. Line insertion techniques for the study of high forest canopies. Selbyana. 2001;22:97-102.

28. Canopy Access Ltd. http://www.canopyaccess.co.uk (2016). Accessed 24 Jun 2016

29. Reid JA. Anopheline mosquitoes of Malaya and Borneo. Stud Inst Med Res Malaysia. 1968;31:1-520.

30. Sallum MAM, Peyton EL, Harrison BA, Wilkerson RC. Revision of the Leucosphyrus group of Anopheles (Cellia) (Diptera, Culicidae). Rev Bras Entomol. 2005:49:1-152.

31. Rattanarithikul R, Harrison BA, Panthusiri P, Coleman RE. Illustrated keys to the mosquitoes of Thailand. I. Background; geographic distribution; lists of genera, subgenera, and species; and a key to the genera. Southeast Asian J Trop Med Publ Health. 2005;36:1-80.

32. Rattanarithikul R, Harbach RE, Harrison BA, Panthusiri P, Jones JW, Coleman RE. Illustrated keys to the mosquitoes of Thailand. II. Genera Culex and Lutzia. Southeast Asian J Trop Med Publ Health. 2005:36:1-97.

33. Rattanarithikul R, Harrison BA, Panthusiri P, Peyton EL, Coleman RE. Illustrated keys to the mosquitoes of Thailand. III. Genera Aedeomyia, Ficalbia, Mimomyia, Hodgesia, Coquillettidia, Mansonia, and Uranotaenia. Southeast Asian J Trop Med Publ Health. 2006:37:1-85.

34. Rattanarithikul R, Harrison BA, Harbach RE, Panthusiri P, Coleman RE. Illustrated keys to the mosquitoes of Thailand. IV. Anopheles. Southeast Asian J Trop Med Publ Health. 2006:37:1-128.

35. Rattanarithikul R, Harbach RE, Harrison BA, Panthusiri P, Coleman RE, Richardson JH. Illustrated keys to the mosquitoes of Thailand. VI. Tribe Aedini. Southeast Asian J Trop Med Publ Health. 2010;41:1-225.

36. R Core Development Team. R: a language and environment for statistical computing. Austria; 2014

37. Oksanen J, Blanchet FG, Kindt R, Legendre P, Minchin PR, O'Hara RB, et al. Vegan: community ecology package. R package version 2.2-1. http:// www.CRAN.R-project.org/package=vegan. 2015.

38. Vavrek MJ. Fossil: palaeoecological and palaeogeographical analysis tools. R package version 0.3.7. https://www.cran.r-project.org/web/packages/ fossil/fossil.pdf. 2015.

39. Bates D, Maechler M, Bolker B, Walker S. Ime4: linear mixed-effects models using Eigen and S4. R package version 1.1-7. http://www.CRAN.Rproject. org/package =Ime4. 2015

40. Jiram Al, Vythilingam I, NoorAzian YM, Yusof YM, Azahari AH, Fong M-Y. Entomologic investigation of Plasmodium knowlesi vectors in Kuala Lipis, Pahang, Malaysia. Malar J. 2012;11:213.

41. Tan CH, Vythilingam I, Matusop A, Chan ST, Singh B. Bionomics of Anopheles latens in Kapit, Sarawak, Malaysian Borneo in relation to the transmission of zoonotic simian malaria parasite Plasmodium knowlesi. Malar J. 2008;7:52

42. Hii JLK, Kan S, Vun YS, Chin KF, Tambakau S, Chan MK, et al. Transmission dynamics and estimates of malaria vectorial capacity for Anopheles bala bacensis and An. flavirostris (Diptera: culicidae) on Banggi island, Sabah, Malaysia. Ann Trop Med Parasitol. 1988;82:91-101.

43. Sinka ME, Bangs MJ, Manguin S, Chareonviriyaphap T, Patil AP, Temperley $\mathrm{WH}$, et al. The dominant Anopheles vectors of human malaria in the AsiaPacific region: occurrence data, distribution maps and bionomic précis. Parasit Vectors. 2011;4:89

44. Hii JLK. Evidence for the existence of genetic variability in the tendency of Anopheles balabacensis to rest in houses and to bite man. Southeast Asian J Trop Med Publ Health. 1985;16:173-82. 
45. Hii JLK, Birley MH, Sang VY. Estimation of survival rate and oviposition interval of Anopheles balabacensis mosquitoes from mark-recapture experiments in Sabah, Malaysia. Med Vet Entomol. 1990;4:135-40.

46. Hii JLK, Chew M, Sang VY, Munstermann LE, Tan SG, Panyim S, et al. Population genetic analysis of host seeking and resting behaviors in the malaria vector, Anopheles balabacensis (Diptera: Culicidae). J Med Entomol. 1991;28:675-84.

47. Eyles DE, Wharton $\mathrm{RH}$, Cheong WH, Warren M. Studies on malaria and Anopheles balabacensis in Cambodia. Bull World Health Organ. 1964;30:7-21.

48. Rundi C. Malaria elimination in Malaysia. Third Annual APMEN technical and business meeting. 9-12 May 2011. Kota Kinabalu; 2011. http://www. apmen.org/apmen-iii-meeting-proceedings/. Accessed 28 Oct 2015.

49. Vythilingam I, Chan ST, Shanmugratnam C, Tanrang H, Chooi KH. The impact of development and malaria control activities on its vectors in the Kinabatangan area of Sabah, East Malaysia. Acta Trop. 2005;96:24-30.

50. Rohani A, Lokman Hakim S, Hassan AR, Chan ST, Ong YF, Abdullah AG, et al. Bionomics of Anopheles balabacensis Baisas, the principal malaria vector in Ranau, Sabah. Trop Biomed. 1999;16:31-8.

51. Wong ML, Chua TH, Leong CS, Khaw LT, Fornace K, Wan-Sulaiman WY, et al. Seasonal and spatial dynamics of the primary vector of Plasmodium knowlesi within a major transmission focus in Sabah, Malaysia. PLoS Negl Trop Dis. 2015;9:e0004135.

52. Manguin S. Anopheles mosquitoes-new insights into malaria vectors. Rijeka: InTech; 2013.

53. Thang ND, Erhart A, Speybroeck N, Xa NX, Thanh NN, Van Ky P, et al. Longlasting insecticidal hammocks for controlling forest malaria: a community-based trial in a rural area of central Vietnam. PLoS One. 2009;4:e7369.

54. Sochantha T, Van Bortel W, Savonnaroth S, Marcotty T, Speybroeck N, Coosemans M. Personal protection by long-lasting insecticidal hammocks against the bites of forest malaria vectors. Trop Med Int Health. 2010;15:336-41.

55. Bates M. Observations on the distribution of diurnal mosquitoes in a tropical forest. Ecology. 1944;25:159-70.

56. Clements AN. The biology of mosquitoes. Vol. 2. In: Sensory reception and behaviour. Wallingford: CABI Publishing; 1999.

57. Bates M. Observations on climate and seasonal distribution of mosquitoes in Eastern Colombia. J Anim Ecol. 1945;14:17-25.
58. Clements AN. The biology of mosquitoes. Vol. 1. In: Development, nutrition and reproduction. Wallingford: CABI Publishing; 1992.

59. Silver JB. Mosquito ecology: field sampling methods. 3rd ed. London: Springer; 2008.

60. Bidlingmayer WL. The effect of moonlight on the flight activity of mosquitoes. Ecology. 1964;45:87-94.

61. Kampango A, Cuamba N, Charlwood JD. Does moonlight influence the biting behaviour of Anopheles funestus? Med Vet Entomol. 2011;25:240-6.

62. Charlwood JD, Paru R, Dagaro H, Lagog M. Influence of moonlight and gonotrophic age on biting activity of Anopheles farauti (Diptera, Culicidae) from Papua New Guinea. Bull Entomol Res. 1986;23:132-5.

63. Birley MH, Charlwood JD. The effect of moonlight and other factors on the ovipositon cycle of malaria vectors in Madang, Papua New Guinea. An Trop Med Parasitol. 1989;83:415-22.

64. Chadee DD. Indoor and outdoor host-seeking rhythms of Anopheles bellator (Diptera: Culicidae) in Trinidad, West Indies. J Med Entomol. 1992;29:567-9.

65. Miller TA, Stryker RG, Wilkinson RN, Esah S. The influence of moonlight and other environmental factors on the abundance of certain mosquito species in light-trap collections in Thailand. J Med Entomol. 1970;7:555-61.

66. Davies JB. Moonlight and the biting activity of Culex (Melanoconion) portesi Senevet \& Abonnenc and C. (M.) taeniopus D. \& K. (Diptera, Culicidae) in Trinidad forests. Bull Entomol Res. 1975;65:81-96.

67. Rubio-Palis Y. Influence of moonlight on light trap catches of the malaria vector Anopheles nuneztovari in Venezuela. J Am Mosq Control Assoc. 1992:8:178-80

68. Souza NA, Andrade-Coelho CA, Silva VC, Peixoto AA, Rangel EF. Moonlight and blood-feeding behaviour of Lutzomyia intermedia and Lutzomyia whitmani (Diptera: Psychodidae: Phlebotominae) vectors of American cutaneous leishmaniasis in Brazil. Mem Inst Oswaldo Cruz. 2005;100:39-42.

69. Singh N, Mishra AK, Curtis CF, Sharma VP. Influence of moonlight on light trap catches of the malaria vector Anopheles culicifacies (Diptera: Culicidae) in India. Bull Entomol Res. 1996;86:475-9.

\section{Submit your next manuscript to BioMed Central and we will help you at every step:}

- We accept pre-submission inquiries

- Our selector tool helps you to find the most relevant journal

- We provide round the clock customer support

- Convenient online submission

- Thorough peer review

- Inclusion in PubMed and all major indexing services

- Maximum visibility for your research

Submit your manuscript at www.biomedcentral.com/submit
() Biomed Central 